\title{
Correction to: The publication trajectory of graduate students, post-doctoral fellows, and new professors in psychology
}

\section{Christopher Zou $^{1} \cdot$ Julia Tsui $^{1} \cdot$ Jordan B. Peterson $^{1}$}

Published online: 13 November 2017

(C) Akadémiai Kiadó, Budapest, Hungary 2017

\section{Correction to: Scientometrics \\ https://doi.org/10.1007/s11192-017-2540-6}

In the original publication, Fig. 6 does not properly label the values. The revised version of the Fig. 6 is given below.

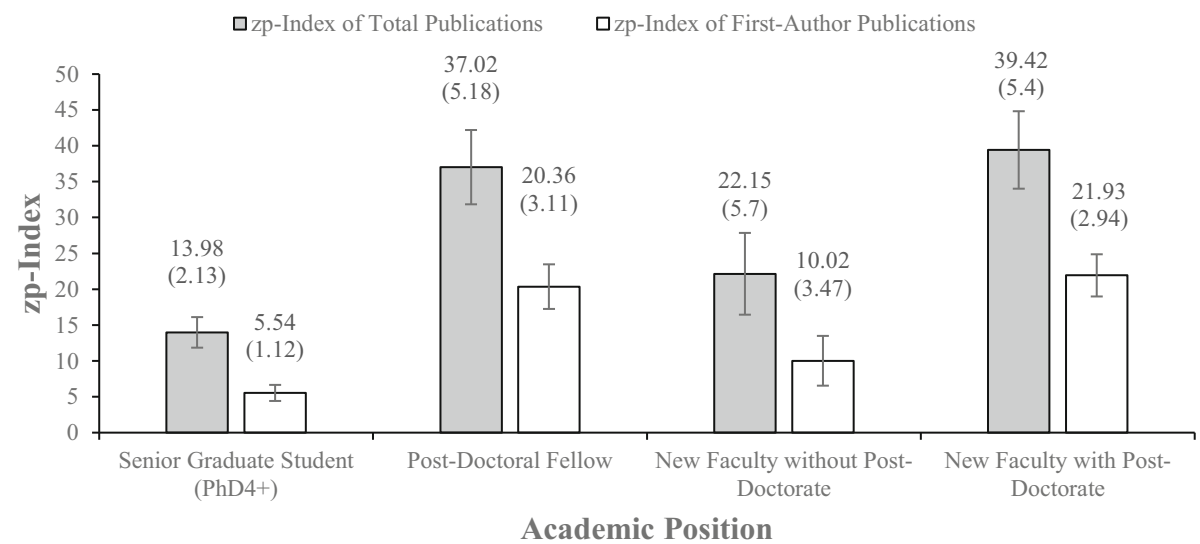

Fig. 6 Comparison of zp-indices between faculty, post-docs and senior graduate students; SD is in brackets

The original article was corrected.

The online version of the original article can be found under https://doi.org/10.1007/s11192-017-2540-6.

$\bowtie$ Christopher Zou

czou@altusassessments.com

1 University of Toronto, Toronto, Canada 